\title{
Redes sociopolíticas e territorialidade na Reserva de Desenvolvimento Sustentável Igapó-Açu (AM, Brasil)
}

\section{Sociopolitical networks and territoriality in the Development Reserve Sustainable Igapó-Açu (Amazonas, Brazil)}

Marilia Gabriela Gondim Rezende - Doutora em Ciências do Ambiente e Sustentabilidade na Amazônia (PPGCASA). Pesquisadora do Núcleo de Socioeconomia (NUSEC) da Universidade Federal do Amazonas (UFAM), . E-mail: mariliageoufam@gmail.com

Therezinha de Jesus Pinto Fraxe - Doutora em Sociologia pela Universidade Federal do Ceará. Professora da Universidade Federal do Amazonas (UFAM), E-mail: tecafraxe@ uol.com.br

Mônica Suani Barbosa da Costa - Pesquisadora do Núcleo de Socioeconomia (NUSEC) da Universidade Federal do Amazonas (UFAM), Mestra em Ciências do Ambiente e Sustentabilidade na Amazônia. E-mail: suanimorena@gmail.com

\section{Resumo}

O Amazonas vem se destacando na criação de Unidades de Conservação (UC), sendo a principal estratégia utilizada por agentes sociais para a conservação da biossociodiversidade. O objetivo deste artigo é analisar as práticas das organizações sociais, e seus desdobramentos territoriais, na governança da Reserva de Desenvolvimento Sustentável/RDS Igapó-Açu, localizada no estado do Amazonas. A metodologia contemplou a realização de entrevistas abertas e a aplicação de formulários entre as famílias residentes na RDS. As organizações sociais têm apresentado função central na RDS Igapó-Açu, pois $67 \%$ das famílias participam de atividades das diferentes formas de ações coletivas. A igreja é a principal organização social atuante na UC, com 43\% de participação das famílias, seguida da Associação de Moradores (ASSAM) e do Conselho Gestor. Portanto, o ordenamento territorial desta unidade é resultado de ações coletivas compartilhas entre grupos sociais, de modo que a distribuição dos objetos espaciais está ligada às territorialidades existentes.

\section{Palavras-chave}

Territorialidade. Ordenamento Territorial. Governança.

\begin{abstract}
The Amazon has been highlighting the creation of Conservation Units (UC), being the main stratagem used for the conservation of biosociodiversity. In this sense, the objective of this article was to understand the social organizations and their territorial unfolding in the governance of RDS Igapó-Açu, located in Amazonas. To achieve this goal, open interviews and application of forms were carried out in $100 \%$ of the families residing in the RDS. It can be inferred that social organizations have played a central role in RDS Igapó-Açu, since 67\% of families participate in activities of different forms of social organization. The church is the main social organization active in the UC, with a $43 \%$ participation of families, followed by the Association of Residents (ASSAM) and the Management Council. Therefore, the territorial ordering of this unit is a result of the imbrication between the different social groups, so that the distribution of space objects is linked to the existing territorialities.
\end{abstract}

\section{Keywords}

Territoriality. Territorial Planning. Governance. 


\section{INTRODUÇÃO}

A Reserva de Desenvolvimento Sustentável (RDS) Igapó-Açu localiza-se no estado do Amazonas, mais precisamente nos municípios de Beruri, Borba e Manicoré (Figura 1), entre os rios Purus e Matupiri. Possui uma área de cerca de 397.557,323ha, cujos limites territoriais fazem fronteira com a Terra Indígena (TI) Cunhã-Sapucaia, com o Projeto de Assentamento Agroextrativista Tupana Igapó-Açu I e II, com o Parque Estadual (PAREST) do Matupiri, com a RDS Rio Amapá, e com o Parque Nacional de Nascentes do Lago Jari. A intersecção de áreas fronteiriças com UC e TI confere um caráter singular à RDS Igapó-Açu.

Figura 1 - Localização da RDS Igapó-Açu

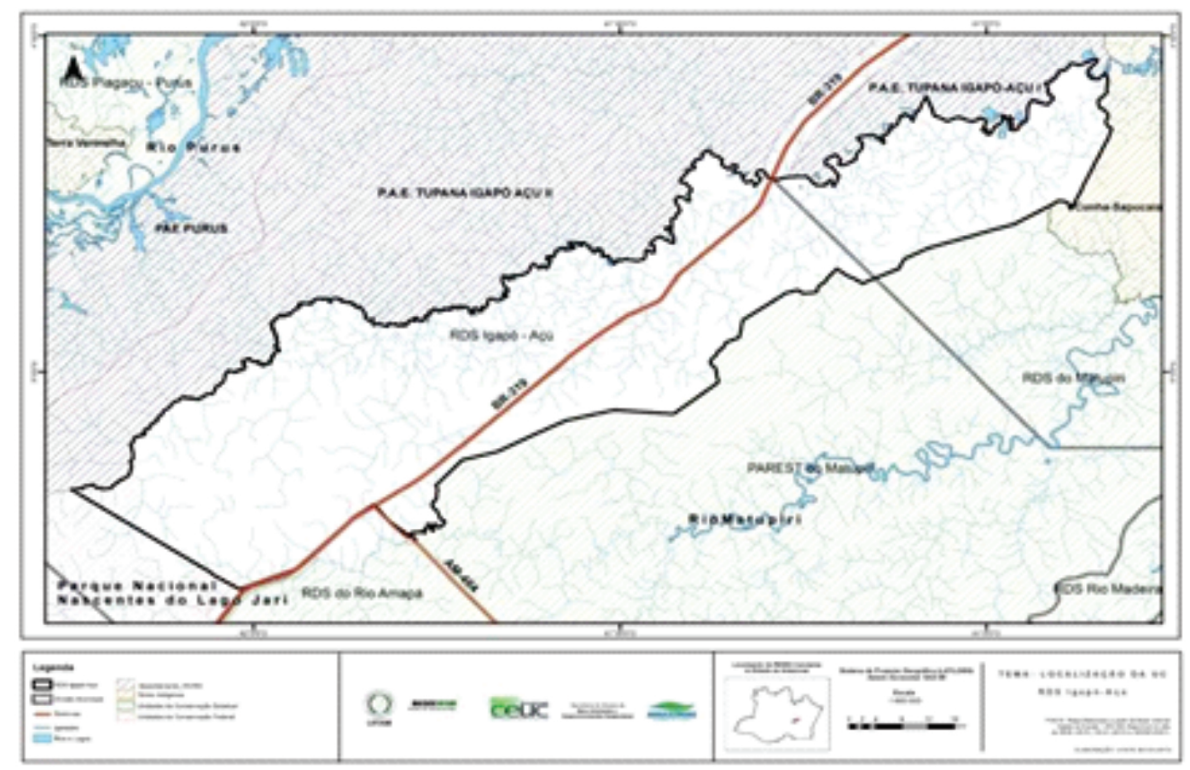

Fonte: Nusec (2015). Organizado por: Rezende e Costa (2015)

A rede de articulação política que configura a governança na RDS IgapóAçu evidencia uma constelação de elementos de suma importância para o entendimento dos desdobramentos e da materialização do poder na unidade política gerida. As formas de organização social emergem, nesse sentido, como importantes denominadores que influenciam consideravelmente na governabilidade e no governo da RDS Igapó-Açu, e promove, consequentemente, impactos significativos na materialização da governança ambiental. 
As organizações sociais são arquétipos de organização pública não estatal que surgem com o objetivo de atender atividades de interesse público e/ ou coletivo. Essas organizações têm um papel importante na configuração do controle social, visto que sua autonomia está para além da influência do Estado, e seus desdobramentos impactam consideravelmente o ordenamento do território e suas ramificações sociais.

A rede de articulação política forma-se a partir da interação entre os sistemas simbólicos e sociopolíticos que originam as organizações sociais e o ordenamento do território. Torna-se imprescindível analisar os desdobramentos dessa interação na governança da área de estudo, em razão dessa ingerência que é intrínseca a esse movimento interacionista.

\section{ORDENAMENTO TERRITORIAL E REDES SOCIOPOLÍTICAS}

A compreensão do ordenamento territorial permite o entendimento da materialização das relações sociais a partir da manifestação do poder no território. Diferentes relações sociais geram diferentes territórios, pois o mesmo configura-se e delimita-se a partir dessas relações e interações societárias. Silva (2000) afirma que o ordenamento territorial se refere ao modo como o território está organizado em razão de suas escalas, tendências, problemas, dentre outros fatores.

O entendimento da organização dos objetos geográficos propicia uma análise abrangente dos fenômenos e epifenômenos sociais organizados. As unidades de conservação apresentam um ordenamento territorial específico, pautado, em sua maioria, nas ações do Plano de Gestão, que é um documento técnico que estabelece normas de uso e ocupação do território delimitado. A RDS Igapó-Açu diferencia-se pela existência de uma rodovia federal em uma área protegida legalmente, isso lhe confere um ordenamento territorial específico, singular se comparado às outras unidades de conservação do Amazonas.

A população é bem diversificada, constituída por povos advindos de diversos municípios do estado do Amazonas (Figura 2). Esse deslocamento populacional justifica-se pelas condições iniciais da BR-319, caracterizada por uma infraestrutura que permitiu a mobilidade de pessoas e mercadorias. A partir dessas condições físicas que a RDS Igapó-Açu foi sendo configurada socialmente, uma congruência de atores sociais de diferentes territórios. A criação da UC ocorreu em 2009, e abarca uma área de aproximadamente 397.557,323ha. 
Figura 2 - Local de nascimento dos moradores da RDS Igapó-Açu

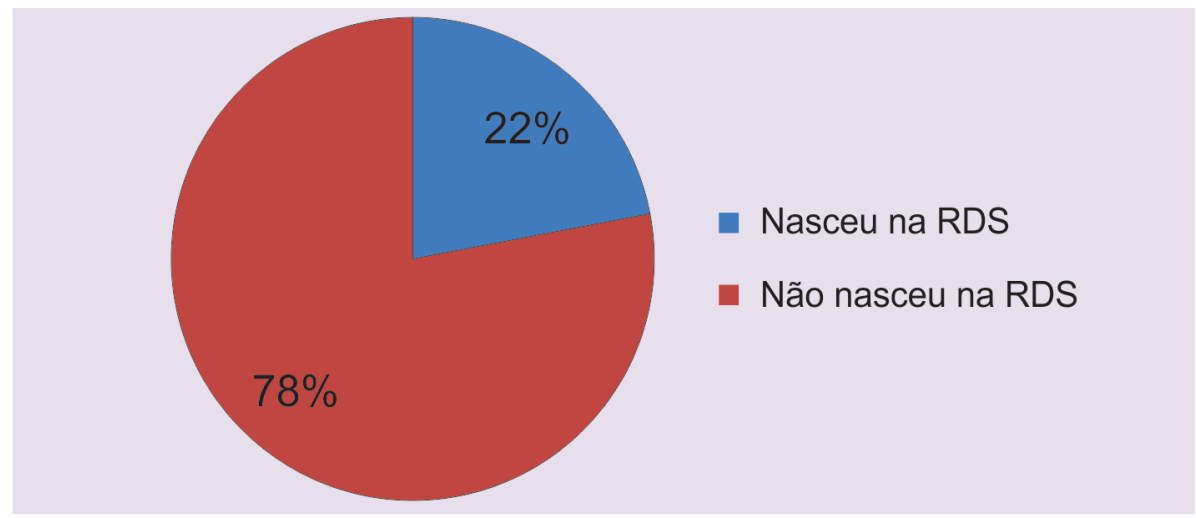

Fonte: Rezende (2016)

Conforme se observa na Figura 2,78\% das famílias que residem na UC não nasceram na RDS, evidenciando uma série de fatores, com destaque para as condições infraestruturais positivas da BR-319 no que concerne ao deslocamento populacional. Dos 78\% que não nasceram na RDS, 57,1\% nasceram em Borba, 28,6\% nasceram em Manaus, e 14,3\% nasceram em Boca do Acre. Inúmeros são os motivos do deslocamento de seu local de nascimento, conforme evidencia a Figura 3.

Figura 3 - Motivos que levaram os atuais residentes a morar na RDS Igapó-Açu

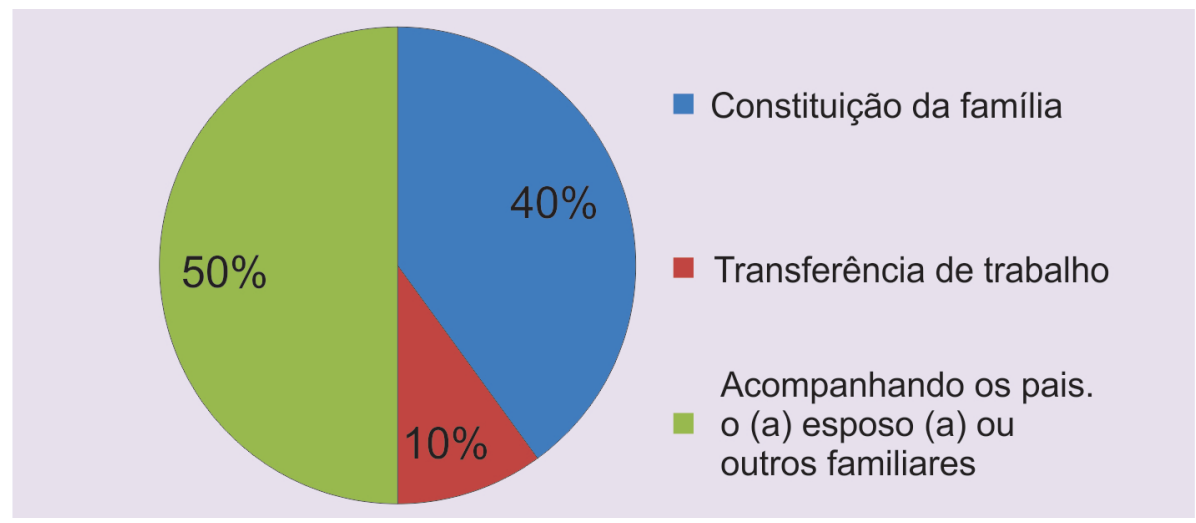

Fonte: Rezende (2016)

Dentre os motivos elencados, $50 \%$ das famílias afirmaram que se deslocaram à UC para acompanhar pais, esposo/esposa, e familiares; $40 \%$ para constituição da família, tendo em vista a abundância de recursos naturais para a reprodução social; e 10\% afirmaram que o deslocamento ocorreu devido à 
transferência de trabalho, com destaque para a necessidade de mão de obra para a expansão da BR e nos respectivos restaurantes que existiam no período de expansão da estrada.

Segundo Gaudemar (1977), a mobilidade espacial ocorre por inúmeros fatores, sendo os principais: a constituição da família, a escolaridade, e a mão-deobra (trabalho). As assertivas desse autor corroboram os dados apontados nessa pesquisa, no que concerne à mobilidade dos residentes da RDS Igapó-Açu.

A escolaridade na RDS Igapó-Açu, ou seja, o término de determinadas etapas de estudo é complexa, pois vários são os elementos que influem nas etapas posteriores ao ensino fundamental. A UC é constituída por apenas uma escola, com turmas de ensino primário e fundamental. A escola apresenta uma infraestrutura formada por duas salas de aula. Não há dificuldades de deslocamento até a escola da RDS, pela localização central que ela estabelece, tanto nos períodos de cheia como na vazante.

Os estudantes que anseiam terminar o ensino fundamental e cursar o ensino médio se deslocam até o município Careiro Castanho, local com escolas de ensino médio. Esse fator tem gerado um crescente deslocamento populacional e explica a prevalência dos dados referentes ao ensino fundamental incompleto, como se pode observar na Figura 4.

Figura 4 - Escolaridade na RDS Igapó-Açu

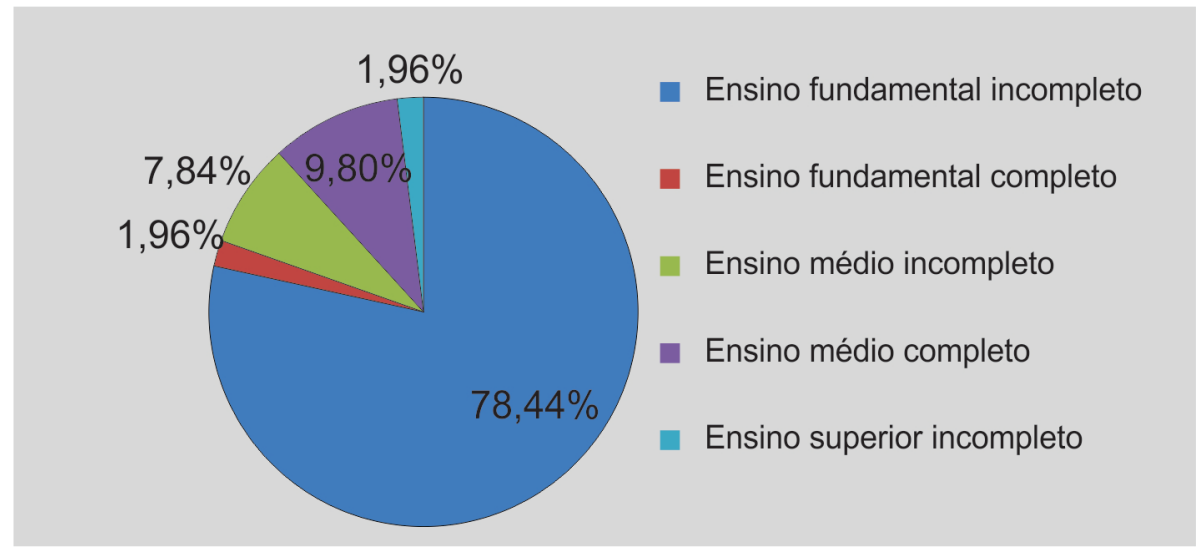

Fonte: Rezende (2016)

Quanto ao tipo de energia fornecida à RDS, 88,9\% advêm do Programa Luz para Todos (Figura 5), que é uma política pública desenvolvida pelo governo federal que objetiva a eletrificação de áreas distantes dos centros urbanos. Embora a garantia dos direitos básicos dos cidadãos seja parte do papel do 
Estado, a sociedade civil organizada da Comunidade São Sebastião do IgapóAçu (a ASSAM) teve forte influência para a instalação da rede elétrica, por meio de reivindicações junto aos órgãos competentes.

Figura 5 - Tipo de energia fornecida à RDS Igapó-Açu

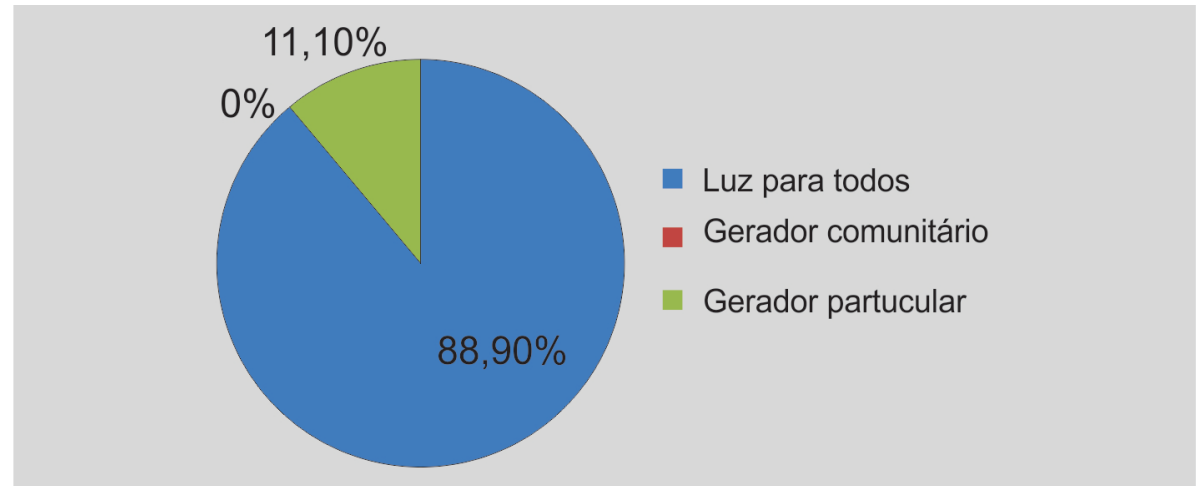

Fonte: Rezende (2016)

Os meios de transporte utilizados na RDS Igapó-Açu são variados, devido aos distintos usos que the são atribuídos. A Figura 6 evidencia que o meio de transporte mais utilizado é o carro (40\%), seguido do barco (26,60\%). O carro é usado para o deslocamento até os municípios de Careiro Castanho e Manaus; o barco e a voadeira para as atividades relacionadas à pesca; a bicicleta e a motocicleta para o deslocamento na comunidade; e o caminhão para o transporte de mercadorias.

Figura 6 - Meios de transporte

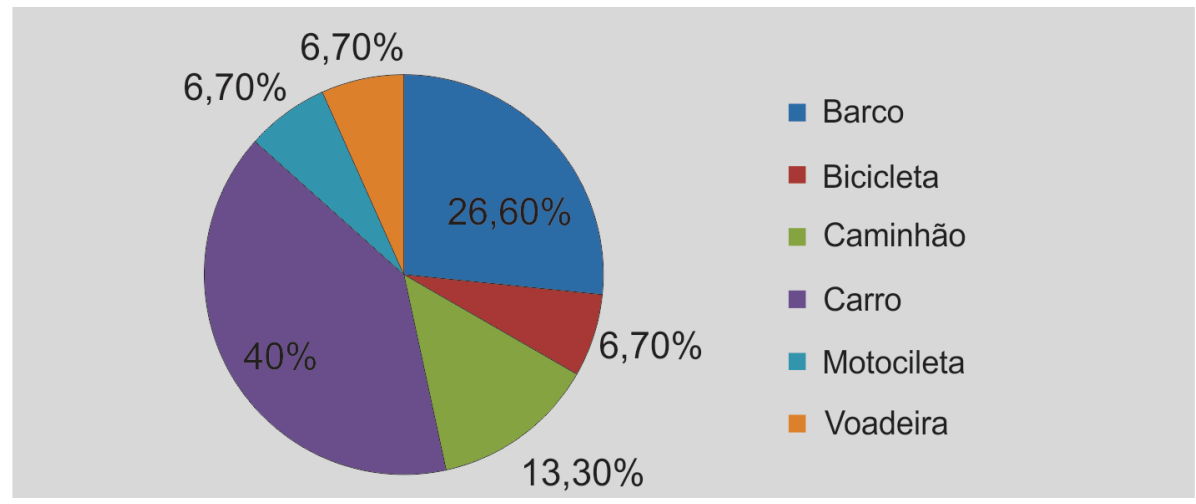

Fonte: Rezende (2016)

Os lugares mais distantes em que os residentes da RDS Igapó-Açu se deslocam são Manaus, Careiro Castanho e Borba (Figura 7). A ida ao Castanho é para visitar os filhos e familiares que estão concluindo os estudos, para consultas 
médicas e para buscar benefícios sociais. Diferentemente da ida à Manaus, que é para participar de cursos profissionalizantes e para fazer compras de produtos que não são encontrados nas adjacências da RDS. Os residentes que vão a Borba têm como objetivo visitar familiares.

Figura 7 - Lugares distantes frequentados pelos residentes

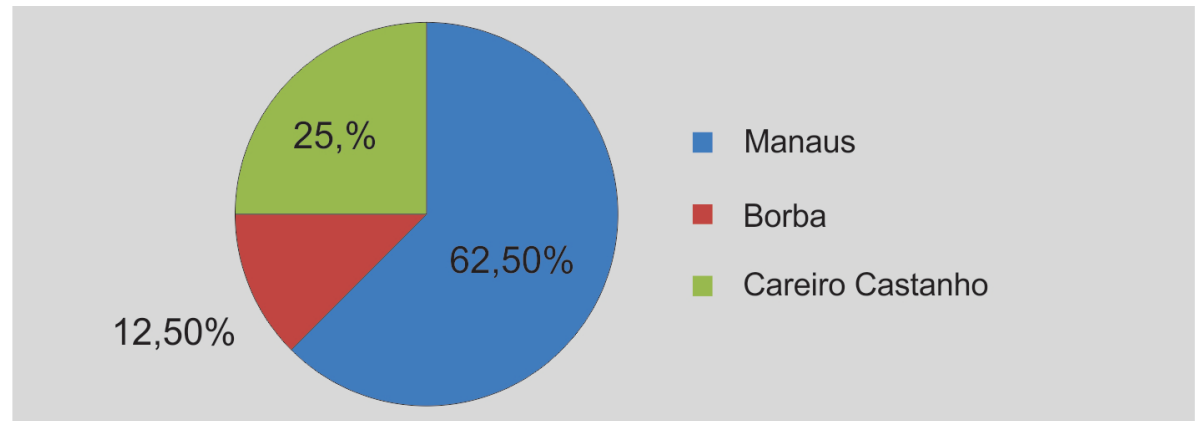

Fonte: Rezende (2016)

A principal fonte de renda das famílias da RDS Igapó-Açu advém da pesca (50\%), do Programa Bolsa Família (18,75\%), da agricultura (12,50\%), da aposentadoria (12,50\%), e de atividades autônomas (6,25\%). A expressividade do número de famílias que tem como principal fonte de renda a pesca, mostra a importância desta atividade econômica na reprodução social da RDS, conforme evidencia a Figura 10.

Essa dependência dos recursos pesqueiros por grande parte da população da RDS Igapó-Açu gerou e tem gerado conflitos territoriais. Segundo Sobreiro e Freitas (2008), desde a década de 1960 os conflitos por pesca vem se intensificando na Amazônia. As regiões que apresentavam e apresentam conflitos latentes são os lagos de várzea, locais de maior pressão por pesca comercial.

Figura 10 - Principal fonte de renda da família

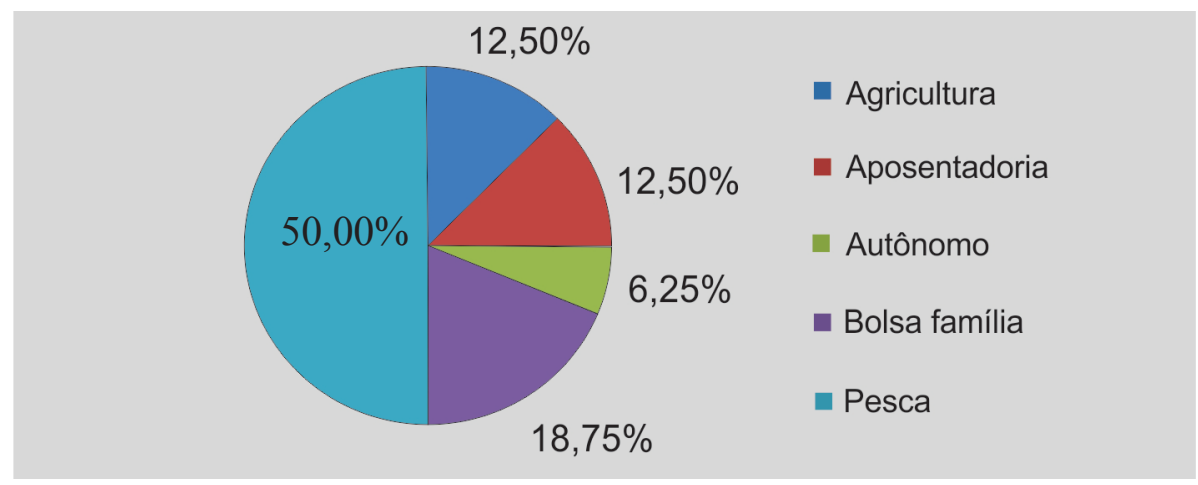

Fonte: Rezende (2016) 
Nos rios de águas pretas os conflitos por pesca estão relacionados com os diferentes modos de apropriação e uso das áreas de pesca (SOBREIRO; FREITAS, 2008). Na Amazônia, de uma maneira geral, e mais precisamente nos rios de água preta, intensificam-se as atividades pesqueiras, principalmente devido à perda de controle local sobre os recursos terrestres (SILVA, 2011). O rio Igapó-Açu apresenta farturas de espécies de peixes, principalmente de tucunaré, essa característica tem atraído os olhares externos à UC, e gerado conflitos territoriais, pelo uso das áreas de pesca e pela exploração de outros recursos naturais, conforme se observa na Figura 9.

Figura 9 - Tipos de conflitos existentes na RDS Igapó-Açu

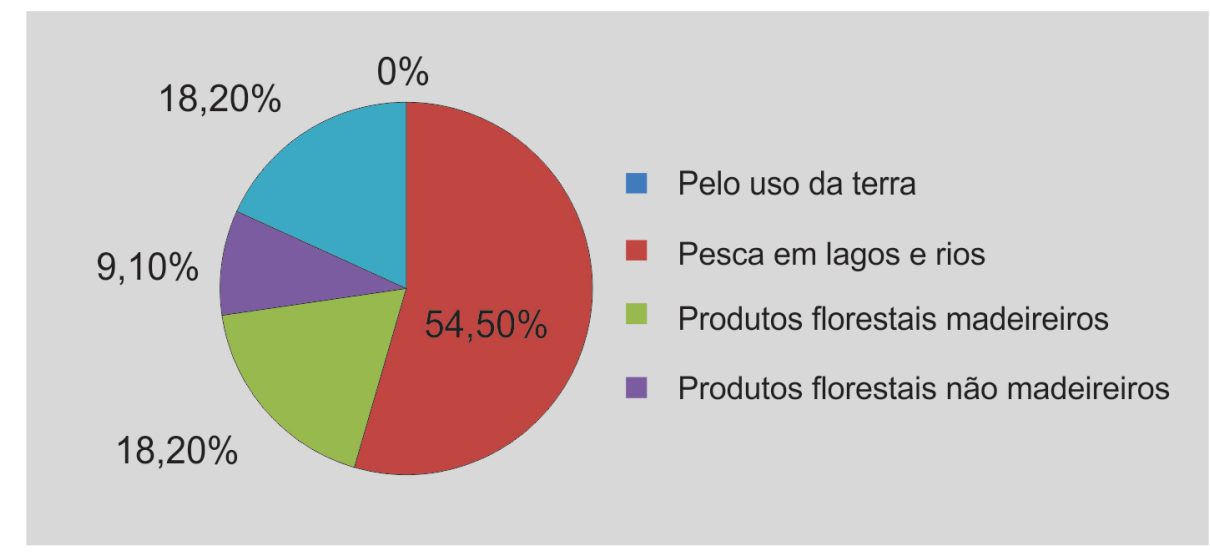

Fonte: Rezende (2016)

O principal conflito citado refere-se à pesca em lagos e rios $(54,50 \%)$, seguido dos conflitos por produtos florestais madeireiros $(18,20 \%)$, conflitos pessoais $(18,20 \%)$, e conflitos por produtos florestais não madeireiros $(9,10 \%)$. Os conflitos em UC são polissêmicos, ou seja, possuem vários significados e ângulos, e variam de acordo com as relações de interesses entre os sujeitos sociais envolvidos.

São resultantes das divergências de pontos de vista e de interesses e envolvem questões sociais, políticas e culturais, com destaque para a luta pela manutenção de territórios. Segundo Thiollent (1998) a divergência é resultante da ambivalência das diferentes ações sociais. Dessa forma, os conflitos territoriais são resultantes de interesses distintos e divergentes, portanto dissimétricos, que se materializam, refletem e são refletidos no território.

Assim sendo, pode-se compreender que os conflitos territoriais existentes na RDS Igapó-Açu são reflexos das relações antagônicas de interesse entre os atores sociais envolvidos. O cadastro e inserção no Seguro Defeso têm obstado 
os conflitos relacionados à pesca, por meio do fornecimento de auxílio financeiro nos períodos necessários à reprodução das espécies de peixes. Nos períodos de defeso, as famílias dedicam-se exclusivamente à agricultura e ao extrativismo.

Essa contextualização e caracterização territorial da RDS Igapó-Açu é imprescindível para a compreensão sistêmica das formas de organização social existentes e para o entendimento da materialização da governança. Assim sendo, as formas de organização social conformam-se a partir da congruência das relações sociais por interesses comuns e, contraditoriamente, divergentes. A coesão social estabelece-se por meio dessas relações e interações sistêmicas.

\section{A TERRITORIALIDADE NA RDS IGAPÓ-AÇU}

Compreender a territorialidade e a territorialização requer importantes inflexões teóricas, dada a complexidade em entender a transindividualidade a partir da noção de território. Essas conceituações devem transcender e remeter às características ônticas e ontológicas do ser no território, que configura a territorialidade a partir de um constante devir. Vários são os autores que trabalham a noção de territorialidade, com destaque para Souza (2001), Spósito (2009), Saquet (2009), Santos (2010), e Haesbaert e Limonad (2007).

Souza (2001), para construir seu conceito de territorialidade, concebe o território a partir da noção de campo de forças de Bourdieu, assim, estabelece algumas formas de territorialidade: a territorialidade cíclica, ou seja, relacionada à temporalidade; a territorialidade móvel, relacionada à fluidez das fronteiras; e a territorialidade em rede, relacionada às tessituras que formam uma malha complexa de territórios descontínuos. Para este autor essas três formas de estabelecimento da territorialidade podem se manifestar concomitantemente, ou seja, em um mesmo território pode haver territorialidades cíclicas, móveis e em redes.

Saquet (2009) conceitua territorialidade como sendo as relações diárias estabelecidas momentaneamente entre os homens e a natureza, é a expressão do cotidiano e do habitus no território. Saquet (2009) critica a noção territorial de Raffestin (1993), pelo tratamento do território como palco das relações destituído dos significados que lhe são intrínsecos, criadores da territorialidade. Desta forma, o autor concebe a territorialidade como a congruência da experiência do cotidiano no território.

Para Santos (2010), a territorialidade é a comunhão estabelecida com o território, são as atividades diárias que os homens executam e que dão vida e vivificam o território. A ausência de territorialidade seria um território sem vida, ou seja, um espaço físico isento de significados, por isso, o autor reitera a 
importância da compreensão da territorialidade para o próprio entendimento do território enquanto espaço produzido.

Os autores ícones, formuladores dos conceitos vigentes de territorialidade, citados anteriormente, foram importantes na medida em que inseriram elementos não trabalhados por outros teóricos. O conceito de territorialidade, aqui trabalhado, será centrado nos autores supracitados, entretanto, outros elementos serão incluídos na compreensão da questão, a partir das lacunas identificadas.

Assim sendo, a territorialidade é o reflexo material e imaterial da ação humana no território. É a congruência resultante da interação entre a dimensão simbólica e a dimensão objetiva. É a expressão do cotidiano, do modo de vida, do habitus dos diferentes grupos sociais intervenientes no território. Compreender a territorialidade destituída desses elementos interagentes significa retirar do território o que lhe é intrínseco.

Na RDS Igapó-Açu a territorialidade estabelece-se principalmente a partir do rio, ele é o elemento principal de condensação territorial, visto que as famílias passam a maior parte do seu tempo em atividades fluviais, seja relacionado à pesca ou ao lazer. Porém, a territorialidade é compreendida como a confluência simbólica e objetiva do fluvial e do terrestre (Figura 10), pois o território formase pela transcendência desses espaços. Os usos desses espaços produzidos, formadores da territorialidade, variam de acordo com o tempo estabelecido pela "natureza", pois os modos de apropriação dos recursos naturais estão diretamente ligados à resiliência ambiental.

Figura 10 - A territorialidade a partir da terra e da água

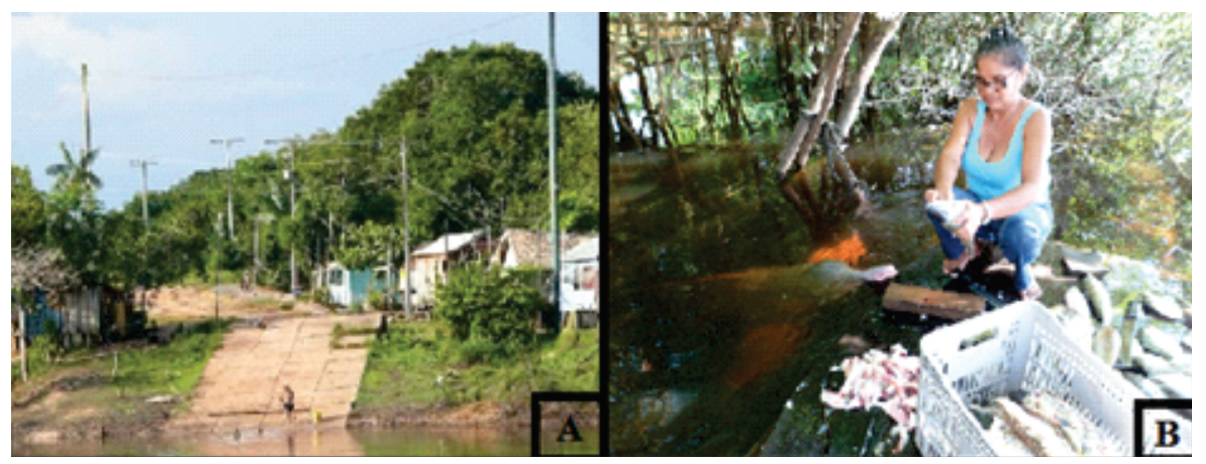

Fonte: Rezende (2016)

Na RDS Igapó-Açu a territorialidade é fundamentada na resiliência do sistema ambiental, pois as atividades desenvolvidas no território são conduzidas pelos modos de vida pautados na sustentabilidade, em suas múltiplas facetas. No período de defeso, as atividades centram-se na agricultura e no extrativismo. 
No período de abundância de recursos pesqueiros, as atividades são voltadas à pesca. O tempo prevalecente é o tempo reprodutor da autopoiese do sistema ambiental, e não o tempo dos interesses humanos. Há uma realocação de ações para a corroboração da sustentabilidade, e a territorialidade se estabelece a partir dessa noção de tempo.

Segundo Hawking e Mlodinow (2005), o tempo está diretamente relacionado ao espaço, de modo que o produto dessa relação é a noção espaçotemporal dos objetos geográficos. As diferentes noções de tempo são socialmente construídas e afirmadas, e estão indissociavelmente ligadas à concepção humana da relação transcendente estabelecida com o espaço.

A territorialidade na RDS Igapó-Açu é fundamentada na interação espaço/tempo, e a noção temporal reflete o trabalho simbólico de apropriação do território. Os significados atribuídos, ou seja, a valoração da "natureza", é que determina e consolida a territorialidade nesta UC, visto que os usos do território variam de acordo com a capacidade de resiliência dos diferentes ecossistemas.

O tempo ocupa papel central no entendimento das relações sociais na RDS Igapó-Açu, pois representa as possibilidades e não possibilidades da ação humana, sendo o fator central de interpretação do território. Atualmente, a modernidade conforma-se a partir de uma sociedade sincrônica, que vive sob a pressão do tempo do relógio econômico. Entretanto, há formações sociais que abdicam desse modo de vida, como é o caso dos grupos sociais da RDS Igapó-Açu.

Ao contrário de uma compressão espaço-tempo (HAESBAERT, 2005), o que se estabelece são formas específicas de uso e apropriação de diferentes espaços por diferentes lógicas temporais. O tempo passa a ser uma sucessão de contextos (ALTHUSSER, 1992), onde as diversas temporalidades coabitam o mesmo período histórico, inserindo uma ordem simbólica e subjetiva inerente à constituição da territorialidade.

A partir da compreensão dos aspectos formadores e conformadores da lógica da territorialidade da RDS Igapó-Açu, pode-se elucidar os aspectos que fundamentam as diferentes formas de organização social desta UC, afinal o modo como a sociedade se organiza está diretamente ligado à sua concepção simbólica de utilização do território. O tópico seguinte apresenta a constituição e o desdobramento das formas de organização social na governança. Esse desdobramento só se torna profícuo por meio dos elementos anteriormente abordados e compreendidos. 


\section{REDES SOCIOPOLÍTICAS, GOVERNANÇA E FORMAS DE ORGANIZAÇÃO SOCIAL}

A territorialidade está intimamente relacionada com a lógica temporal que conduz as ações dos diferentes atores sociais, como foi elencado anteriormente. A forma com que os grupos sociais se organizam relaciona-se inteiramente com a essência simbólica que comanda as decisões e ações objetivas. As formas de organização social emergem, nesse sentido, como um produto do conjunto das relações sociais projetadas.

Segundo Etzioni (1967) existem vários tipos de organizações: as organizações coercitivas, onde o poder é instituído por meio da força física e a principal forma de controle manifesta-se por meio de punições; as organizações utilitárias, onde o poder institui-se por meio do controle aos incentivos econômicos, e o controle manifesta-se por meio dos benefícios ansiados; e as organizações normativas, onde o controle moral ocupa papel central, e o poder é expresso por meio do envolvimento simbólico e motivacional.

Etzioni (1967) a partir de sua teoria estruturalista das organizações psicossociais deixou algumas lacunas em suas pesquisas, pelo fato de ter tratado as organizações a partir unicamente da lógica do controle. Porém, teve contribuições importantes no entendimento da organização das unidades sociais e de seus reflexos. Na RDS Igapó-Açu existem várias formas de organização social, cada uma objetivando seus interesses particulares. Os resultados da pesquisa mostram que $66,70 \%$ das famílias participam de organizações sociais. Do total de famílias partícipes, 42,90\% frequentam igreja, 35,70\% participam da Associação de Moradores, e 21,40\% participam do Conselho Gestor.

Figura 11 - Participação em organização Figura 12 - Organização social partícipe social

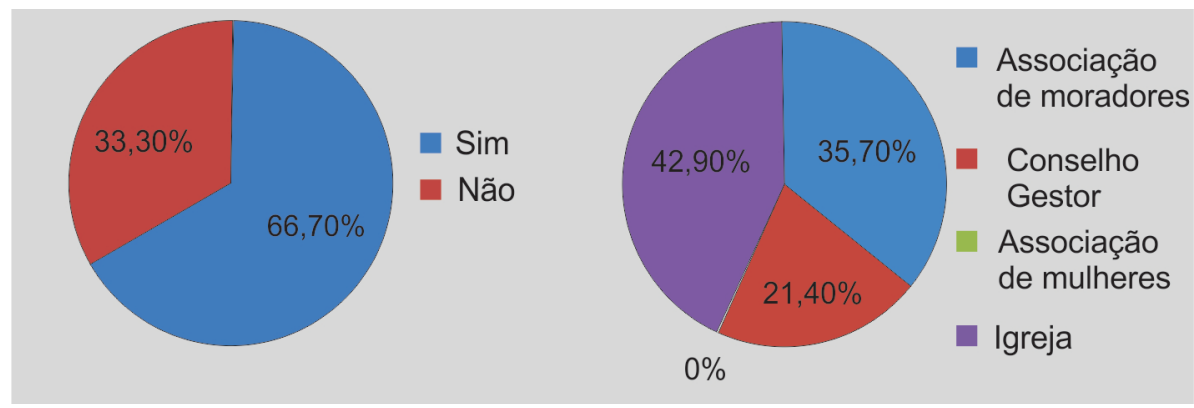

Fonte: Rezende (2016) 
A significativa participação das famílias na igreja justifica-se por inúmeros fatores: pela reterritorialização do sagrado instituído socialmente nos locais de nascimento e socialização; pela necessidade de encontro fraternal e vivificação espiritual proporcionado pelos encontros religiosos; e pela realização de festas religiosas.

Fraxe (2004) afirma que a Igreja Católica possuiu e possui um papel central nas comunidades rurais do Amazonas, por ser uma instituição política, cultural e social que se insere no cotidiano dos povos. A autora evidencia a importância da igreja na configuração socioespacial das comunidades e suas imbricações. A religião prevalecente na RDS Igapó-Açu é o catolicismo, representativo de 85,70\% das famílias (Figura 14).

Figura 13 - Detenção de crença Figura 14 - Crença religiosa das religiosa famílias
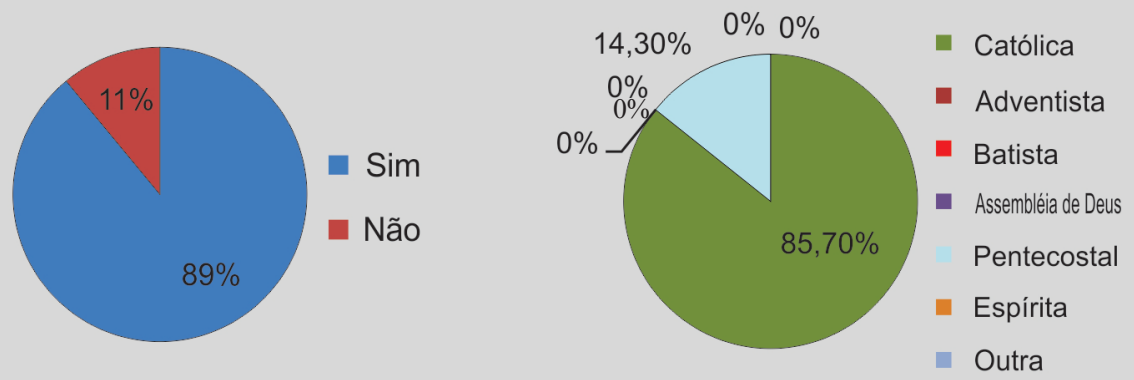

Fonte: Rezende (2016)

A comunidade São Sebastião do Igapó-Açu possui diversos festejos religiosos, com destaque para as festas de São Pedro, de São João, do Sagrado Coração de Jesus, e para a Festa dos Santos. As festas religiosas, além de serem vistas como momentos de diversão e de alimentação espiritual, são períodos de reafirmação cultural e reinvenção da tradição, pois corroboram por meio da socialização os elementos simbólicos produtores do cotidiano.

Dessa forma, na RDS Igapó-Açu, as festas apresentam-se como manifestações culturais de afirmação das relações de vizinhança e dos laços de religiosidade, que constituem as redes de sociabilidade formadoras de identidades e de topofilia. Além das festas religiosas, há festas temáticas, como a Festa do Tucunaré, conhecida em escala estadual, por congregar pessoas de diversos municípios do Amazonas. Observa-se que há festas na comunidade, como a Festa do Tucunaré destinada ao público externo e voltada ao turismo; e festas da comunidade, organizadas com vistas a atender os residentes, uma festa interna. 
Segundo Perez (2002), as festas são rituais que ocorrem em diferentes sociedades, são atos simbólicos que evidenciam a organização social e a sociabilidade dos grupos sociais territorializados. Nos momentos festivos os espaços são ressignificados, de acordo com o público (externo ou interno) e com o que se deseja explicitar.

Assim sendo, as festas na RDS Igapó-Açu representam o que Mauss (2003) denomina de fato social total, pois os rituais expressam todas as dimensões da vida (social, religiosa, cultural, econômica, estética, dentre outras) que constituem o sistema social em sua totalidade. As diferentes sociabilidades compõem o quadro festivo e lhe dão vida.

A compreensão das formas de organização social perpassa o âmago das sociabilidades, da socialização, das formas sociais, das ressignificações, dos significados, e dos sistemas simbólicos. Somente a partir da interação entre esses fatores, complementares e cônjuges, que as formas de organização social podem ser tratadas claramente. Nas comunidades rurais, como é o caso da RDS IgapóAçu, essa interação é cada vez mais fortalecida e revelada, pela topofilia criada e estabelecida pelos grupos sociais.

A socialização quanto ao trabalho e a inserção nas atividades produtivas começam na infância. A Figura 15 mostra a divisão social do trabalho por idade, pode-se observar que $75 \%$ das famílias não dividem o trabalho por faixa etária, as crianças são inseridas nas atividades de trabalho logo na infância, porém em atividades com menor esforço físico.

Figura 17 - Divisão social do trabalho por faixa etária

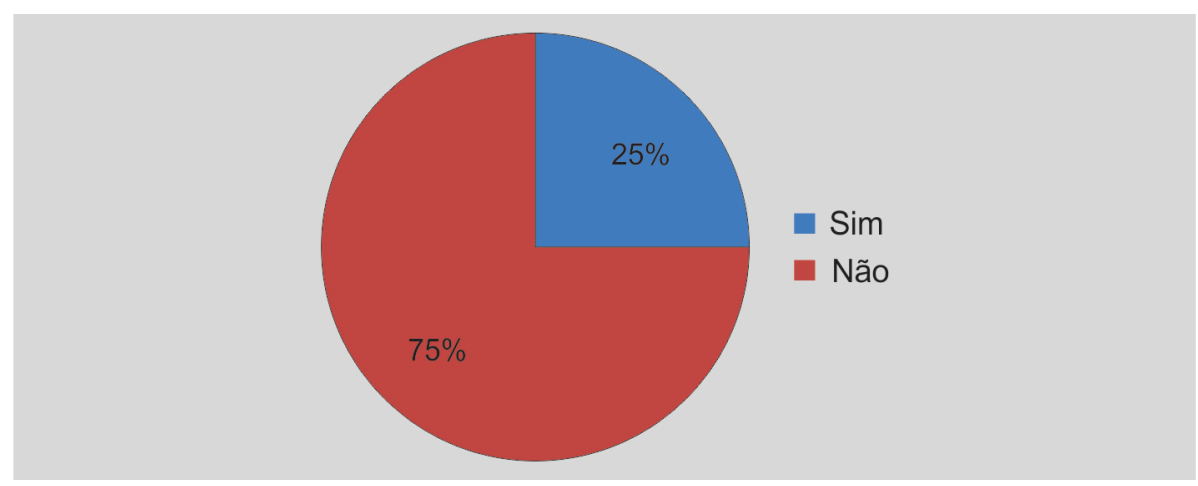

Fonte: Rezende (2016)

A inserção das crianças nas atividades de pesca e agricultura objetiva a transferência dos conhecimentos tradicionais adquiridos e perpassados por meio da socialização intergeracional; o fortalecimento dos laços familiares; e o 
aprendizado das técnicas perceptivas de sensibilização das características dos ecossistemas os quais estão inseridos. Leal (2010), em seus estudos sobre a socialização em comunidades rurais, afirma que:

É nesse momento de reconhecimento da infância que se percebe que é a criança que perpetua o modo de vida. Que é ela ao aprender e ao reproduzir o aprendido que torna re-existente em sua geração aquele saber, aquele fazer, aquele modo de vida (LEAL, 2010, p. 123).

Nesse contexto de perpetuação de valores e símbolos que se justifica a não distinção de faixa etária no trabalho na RDS Igapó-Açu. Não há indisposição das crianças no processo de aprendizagem de atividades como caça, pesca e agricultura. A participação nessas atividades está cristalizada no imaginário social da comunidade, criador dos sistemas simbólicos.

Na RDS Igapó-Açu há vários tipos de família: famílias díades nucleares, aquela em que os cônjuges não possuem filhos e nem parentesco em comum; famílias nucleares, com apenas um nível de descendência; e famílias extensas, com níveis de ascendência e descendência variados. Essa diversificação de tipos familiares justifica-se pela pluralidade de atores sociais que se deslocaram à UC no ápice do asfaltamento da BR-319.

Essas características são importantes para o entendimento da rede de articulação política que estabelece a governança ambiental, pois o modo como os atores sociais criam as relações de poder está intimamente relacionado com os sistemas simbólicos geradores dos sistemas sociopolíticos. Essa trama de relações e interações gera o governo da RDS Igapó-Açu, a partir da manifestação do poder e de seus desdobramentos sociais e, consequentemente, territoriais.

\section{CONSIDERAÇÕES FINAIS}

Os caminhos indicados pela pesquisa conduzem a análise da governança ambiental e das redes sociopolíticas para novos traçados, anteriormente não previsíveis. A ressignificação do conceito de governança ambiental foi o foco deste artigo. A governança estabelece-se a partir de inúmeros elementos: governabilidade, governo, relações de poder, territorialidades, temporalidades, sistemas simbólicos, sistemas sociopolíticos, formas de organização social, escalas, dentre outros.

A governabilidade apresenta-se como o conjunto de condições necessárias para o desenvolvimento do governo, elemento conformador da governança. As relações de poder apresentam-se como a característica básica que estabelece as 
formas de organização social. Os sistemas simbólicos, criados pelo imaginário social, formam os sistemas sociopolíticos, que são a expressão material da governança. As temporalidades distintas configuram as territorialidades, que são as práticas sociais objetivadas via subjetividade. Todos esses elementos, simétricos e dissimétricos, geram e corroboram, dialeticamente, a governança ambiental.

Essa governança ambiental transcende as fronteiras dos Estados Nacionais, e necessita de um tratamento transescalar dos fenômenos e epifenômenos sociais. Essa transcendência justifica-se pela significativa abrangência da governabilidade, que é conduzida por atores sociais de diversas partes do mundo. Além da escala internacional, explicada acima, destaca-se a importância e os impactos da escala nacional no contexto local, como a promulgação da Lei n⿳⺈ 6.938/91, que corroborou a Política Nacional do Meio Ambiente, e disseminou importantes políticas públicas para as UC do Brasil, e em especial para as da Amazônia brasileira.

Doravante, a governança ambiental constitui-se via transescalar. Em micro escala forma-se por meio da interação entre os sistemas simbólicos e os sistemas sociopolíticos. Em macro escala, condensa os diferentes elementos formadores da governabilidade e das políticas públicas. As formas de organização social fundamentam-se a partir de elementos transescalares, por isso a governança ambiental é transescalar.

Vários são os fatores que contribuíram para o estabelecimento atual da governança ambiental na RDS Igapó-Açu: a existência da BR-319, o deslocamento populacional por meio de incentivos estatais, o anseio pela constituição familiar em locais com abundância de recursos naturais, dentre outros fatores. Esses foram os principais elementos históricos que consolidaram o atual sistema sociopolítico da UC.

A significativa concentração populacional advinda de outros municípios $(78 \%)$ conferiu e confere um ordenamento territorial específico à RDS IgapóAçu, visto que os atores sociais tendem a reproduzir territorialmente os espaços vivenciados em seus locais anteriores de vivência. Os ecletismos das roças, das escolhas das áreas de pesca, do gosto pelas diferentes formas de lazer, conduzem a análise da governança cada vez mais para as formas de organização social.

A família exerce, nesse contexto, forte influência na continuidade do modo de vida pautado na sustentabilidade ambiental, pois a partir da reprodução cultural, insere as crianças na lógica simbólica das práticas sociais cotidianas, configurando assim a territorialidade, importante elemento analítico para a compreensão da governança. Aliado à família, a igreja emerge como a organização social mais ativa na RDS Igapó-Açu, com participação de 43\% das famílias. 
As festas da comunidade e na comunidade são momentos cruciais de observação da organização da governança. Elas evidenciam e fortalecem os sistemas simbólicos e demonstram substancialmente as relações de poder existentes e seus desdobramentos territoriais. Dessa forma, os festejos exercem função imprescindível na materialização da governança, em suas múltiplas escalas, e na reafirmação cultural e reinvenção da tradição.

A governança ambiental na RDS Igapó-Açu é uma governança democrática, que, a partir do Conselho Gestor, incrementa a participação de diferentes atores sociais, com diferentes pontos de vista e interesses. Ao invés de uma governança cosmopolita, o que se estabelece é uma forma democrática de governação dos processos de tomada de decisão.

\section{AGRADECIMENTOS}

À Coordenação de Aperfeiçoamento de Pessoal de Nível Superior (CAPES) pelo financiamento da pesquisa. A todos os residentes da Reserva de Desenvolvimento Sustentável Igapó-Açu, que contribuíram no processo de artesanato intelectual.

\section{REFERÊNCIAS}

ALTHUSSER, L. O futuro dura muito tempo. Paris: Editora Companhia das Letras, 1992.

BOURDIEU, P. O poder simbólico. Rio de Janeiro: Bertrand Brasil, 2005.

ETZIONI, A. Organizações modernas. São Paulo: Editora Pioneira, 1967.

FRAXE, T. J. P. Cultura cabocla-ribeirinha: mitos, lendas e transculturalidade. São Paulo: Annablume, 2004.

GAUDEMAR, Jean-Paul de. Mobilidade do trabalho e acumulação do capital. Lisboa: Editora Estampa, 1977.

HAESBAERT, R. A produção capitalista do espaço. São Paulo: Annablume, 2005.

HAESBAERT, R.; LIMONAD, E. O território em tempos de Globalização. Revista Eletrônica de Ciências Sociais Aplicadas, Rio de Janeiro, v. 1, n. 2, p. 39-52, 2007.

HAWKING, S; MLODINOW, L. Uma nova história do tempo. Rio de Janeiro: Ediouro, 2005. 
LEAL, A. Olhar o ser, ver o acontecer: socialização e comunidade. Revista Caminhos da Geografia, Uberlândia, v. 11, n. 34, p. 123-130, 2010.

MAUSS, M. Ensaio sobre a dádiva: forma e razão da troca das sociedades arcaicas. In: MAUSS, M. Sociologia e Antropologia. São Paulo: Cosac Naify, 2003.

PEREZ, L. F. Antropologia das efervescências coletivas. In: PASSOS, Mauro. A festa na vida. Petrópolis: Vozes, 2002.

RAFFESTIN, C. Por uma geografia do poder. São Paulo: Editora Ática, 1993. REZENDE, M. G. G. Governança ambiental na Reserva de Desenvolvimento Sustentável Igapó Açu (Amazonas, Brasil). Dissertação apresentada ao Programa de Pós-Graduação em Ciências do Ambiente e Sustentabilidade na Amazônia, 2016.

SANTOS, M. Abordagens e concepções de território. 2 ed. São Paulo: Expressão Popular, 2010.

SAQUET, M. A.; BRISKIEVICZ, M. Territorialidade e identidade: um patrimônio no desenvolvimento territorial. Caderno Prudentino de Geografia, Presidente Prudente, v. 1, n. 31, p. 03-16, 2009.

SILVA, A. L. da. Entre tradições e modernidade: conhecimento ecológico local, conflitos de pesca e manejo pesqueiro no rio Negro, Brasil. Boletim do Museu Paraense Emílio Goeldi. Ciências Humanas, Belém, v. 6, n. 1, p.141-163, 2011. SILVA, C. N. O sistema de gestão do território em Portugal. Revista de Ação Regional e Local, FAQ, Lisboa, XIV (74), p. 21-35, 2000.

SOBREIRO, T.; FREITAS, C. E. de C. Conflitos e territorialidade no uso de recursos pesqueiros do Médio rio Negro. In: IV Encontro Nacional da Anppas. Brasília, 2008. Anais eletrônicos... Brasília: ENANPPAS, 2008. Disponível em: <http:/ / www.anppas.org.br/encontro4/cd/gt2.html >. Acesso em 16 ago. 2018.

SOUZA, M. L. O território: sobre espaço e poder, autonomia e desenvolvimento. In: CASTRO, I. E. et al. Geografia: conceitos e temas. 3. ed. Rio de Janeiro: Bertrand Brasil, 2001.

SPOSITO, M. E. B. Introdução. In: SAQUET, M. A.; SPOSITO, E. S. (Org.). Território e Territorialidades: teorias, processos e conflitos. 1 ed. São Paulo: Expressão Popular, 2009. p. 7 -10.

THIOLLENT, M. J. M. Metodologia da pesquisa-ação. São Paulo: Cortez, 1998. 